\title{
Gonorrhoea in the Chimpanzee Infection with laboratory-passed gonococci and by natural transmission
}

\author{
W. JERRY BROWN, C. T. LUCAS, AND U. S. G. KUHN \\ Venereal Disease Research Laboratory, Venereal Disease Branch, State and Community Services Division, \\ Center for Disease Control, Health Services and Mental Health Administration, Public Health Service, \\ U.S. Department of Health, Education, and Welfare, Atlanta, Georgia 30333, U.S.A.
}

Recent studies at this laboratory have shown that the male chimpanzee can develop gonococcal urethritis after the intra-urethral inoculation of human urethral exudate containing Neisseria gonorrhoeae (Lucas, Chandler, Martin, and Schmale, 1971). Other workers (Kellogg, Cohen, Norins, Schroeter, and Reising, 1968) were able to show that the Type 1 colonies of $N$. gonorrhoeae (strain F-62) were still virulent for male volunteers after 720 selective transfers in vitro. It seemed of interest to determine whether gonococci passed in vitro were able to infect the chimpanzee. We report here infection by organisms selectively passed six times in vitro, and we also describe natural transmission of gonorrhoea from male to female chimpanzee.

\section{Material and methods}

The strain of gonococcus used for inoculation was isolated on Thayer-Martin (TM) selective medium (Thayer and Martin, 1964) from the endocervix of an infected human female. Selective transfers of colony Types 1 and 2 were made every 24 hours on GC Medium Base (GCB, Difco), enriched with a defined supplement (White and Kellogg, 1965). At each transfer, the organisms were incubated for $24 \mathrm{hrs}$ in a candle extinction jar at $35^{\circ} \mathrm{C}$. After the sixth selective transfer, the gonococci were suspended in $5 \mathrm{ml}$. of trypticase-soy broth (BBL) to an optical density of 0.4 at a wavelength of $530 \mu$. This gave a yield of approximately $2 \times 10^{7}$ colonyforming units per $\mathrm{ml}$. as determined by dilution plate counts. $30 \mathrm{~min}$. elapsed between the preparation of the suspension and the inoculation of the organisms. $2 \mathrm{ml}$. inoculum were introduced into the urethra of a male chimpanzee as previously described by Lucas and others (1971).

Preinoculation specimens from the male chimpanzee were collected from the animal's urethra, rectum, and nasopharynx, and streaked on to TM selective medium. Specimens were also taken from the endocervix, rectum, and nasopharnyx of the female chimpanzee.

Received for publication February 4, 1972

Trade names are used for identification only and do not represent an endorsement by the Public Health Service or the U.S. Department of Health, Education, and Welfare.
The criteria for the diagnosis of gonorrhoea in both animals were the same as in the previous study (Lucas and others, 1971). The organism had to grow on TM selective medium, give a positive oxidase reaction, show Gram-negative diplococci when stained, produce acid without gas upon fermentation of glucose, and fail to ferment maltose.

After the male developed a positive urethral culture for $N$. gonorrhoeae, he was placed in a cage with a compatible female chimpanzee. They were observed having frequent sexual intercourse beginning on the first day of cohabitation.

The development of serum antibodies to gonococci was determined by a complement-fixation test (Peacock, 1971) and by an indirect fluorescent antibody test (Welch, O'Reilly, and Kellogg, 1971).

\section{Findings}

All preinoculation cultures were negative for $N$. gonorrhoeae, and all preinoculation sera were nonreactive in the serological tests for gonococcal antibodies. In the case of the male chimpanzee, the urethral specimen was found to be culturally positive for $N$. gonorrhoeae on TM selective medium at the first culture taken 3 days after inoculation. No clinical signs of urethritis were evident until the 10th up to the 15th day after inoculation, during which time a slight urethral discharge was observed. This exudate contained intracellular Gram-negative diplococci. Organisms persisted in the male urethra until the 49th day after inoculation.

For the female chimpanzee, the cervical specimen was found to be positive for $N$. gonorrhoeae on TM selective medium at the first postexposure culture taken 5 days after she had been caged with the infected male. Gonococci were then recovered from the endocervix until the 39th day after exposure.

After inoculation, complement-fixing antibodies appeared in the male chimpanzee at 21 days, but failed to appear in the female chimpanzee. By using the indirect fluorescent technique, antibodies were detected in the male by 15 days and in the female by 18 days. A further report will give details of the serological results. 


\section{Discussion}

These observations establish that a culture of $N$. gonorrhoeae, selectively passed six times in vitro, can infect chimpanzees, and that the subsequent infection can be venereally transmitted from male to female. The six passages of the gonococci were determined by two factors-obtaining a pure culture of Types 1 and 2 gonococci, and scheduling the examinations of the chimpanzee. First, the organism was isolated on TM selective medium and transferred on to GC medium base where colony types could be determined and selectively picked. Secondly, the chimpanzee used in this study had to be examined by culture and blood tests beforehand. Chimpanzees can be safely examined twice a week using Vetalar* (Katamine hydrochloride) as an immobilizing agent. Pre-examination of the animal and rescheduling for inoculation required at least 6 days. Though the six passages are far fewer than the 720 which Kellogg used in showing maintenance of virulence for humans, the results suggest that studies of animal models of gonorrhoea could be based on organisms appropriately passed in vitro.

The male chimpanzee showed a slight urethral discharge from the 10th to the 15th day after inoculation. The possible presence of a vaginal discharge resulting from the gonococcal infection could not be ascertained in the female at the time of the first recovery of gonococci because of her concurrent menstruation; however, no inflammatory discharge was evident during the following weeks.

The ability of the in vitro-passed organisms to infect the animals supports the earlier work by Lucas and others (1971). However, there appeared to be a difference in the clinical picture between their male chimpanzees receiving human exudate and the male chimpanzee in this experiment receiving gonococci maintained in vitro. This male chimpanzee exhibited only a slight discharge for a period of 5 days, beginning on the 10th day after inoculation. The previous male chimpanzees receiving the human exudate inoculum developed a slight urethral discharge on the 4th day, and their exudates were very prominent from the 7th to the 14th day, decreasing by the 18th day and absent by Day 30 .

In our laboratory natural transmission of gonococci from male to female chimpanzee has been previously observed in one other instance. A male chimpanzee which had been infected with fresh human urethral exudate infected his female cagemate at some time within a 3-week period. Natural transfer between the two chimpanzees in the present study was shown to occur within 5 days. The fact that

$\star$ Parke, Davis and Co. these two female chimpanzees could be infected with gonorrhoea, and that both animals showed no obvious signs of their infection, suggests that female chimpanzees might serve as animal models for the 'asymptomatic' carrier state seen in human females with gonorrhoea. Important factors of natural transmission in chimpanzees no doubt relate to their sexual habits, e.g. the aggressiveness of the male and the receptivity of the female. She is usually more receptive between the 8 th and 18 th days of the menstrual cycle; however, a female will accept an aggressive male during other times to avoid being attacked (Rogers, 1971). The latter seemed to be the case with these chimpanzees, because the female had sexual contact with her male cagemate during her menstrual period.

\section{Summary}

A male chimpanzee developed gonococcal urethritis after inoculation with a pure culture of Neisseria gonorrhoeae which had been selectively passed six times in vitro. The infection was venereally transmitted to a female cagemate, as evidenced by positive cervical cultures and the development of gonococcal antibodies in that animal.

The authors thank Mr. William L. Peacock, Jr., and Mr. Bobby G. Welch for their technical assistance.

\section{References}

Kellogg, D. S., Cohen, I. R., Norins, L. C., Schroeter, A. L., and ReISING, G. (1968) F. Bact., 96, 596

Lucas, C. T., Chandler, F., Martin, J. E., and Schmale, J. D. (1971) F. Amer. med. Ass., 216, 1612

PeACOCK, W. L. (1971) HSMHA Hlth Rep., 86, 706

Rogers, C. M. (1971) Yerkes Regional Primate Center, Atlanta, Georgia, Personal communication.

Thayer, J. D., and Martin, J. E. (1964) Publ. Hlth Rep. (Wash.), 79, 49

WeLCH, B. G., O'ReILly, R. J., and KeLlogG, D. S. (1971) In preparation

White, L. A., and Kellogg, D. S. (1965) Appl. Microbiol., 13, 171

La gonococcie du chimpanzé. Infection par des gonocoques entretenus au laboratoire et par transmission naturelle

SOMMAIRE

Un chimpanzé mâle présenta une urétrite gonococcique après inoculation d'une culture pure de Neisseria gonorrhoeae qui avaient été passés sélectivement six fois in vitro. L'infection fut transmise sexuellement à une femelle maintenue dans la même cage, comme ceci fut prouvé par la positivité de cultures cervicales et l'apparition d'anticorps gonococciques chez cet animal. 